Royal Navy. The reader will discover some surprising finds in this book and it is interesting to find out how civilian and naval dentistry and dental education have impacted upon and influenced each other. Compared to the numerous thick and heavy hard-back dental books out there, this is a much more appropriate material for bed-time reading!

A. Lei

\section{ORAL REHABILITATION:} A CASE-BASED APPROACH

$\begin{array}{ll} & \begin{array}{l}\text { Iven Klineberg, Diana Kingston } \\ \text { (eds) }\end{array} \\ \text { URAL: Wiley-Blackwell } \\ \text { ISBNA } 9781405197816\end{array}$

This is a well presented book that looks at treatment planning and management of various restorative cases, from single tooth restorations to full mouth rehabilitation. The book itself arose from the teaching philosophies taught as part of the speciality programme in prosthodontics at the University of Sydney. Many of the cases presented in the book are from recent graduates of this programme.

It is divided into four main sections compromising of 15 chapters, all of which follow a methodical and logical order. Throughout the book, there is excellent use of clinical photography with most cases having pre-, mid- and postoperative images available. The book is well written - -following a repetitive layout for all of the cases presented. Furthermore, there is substantial demonstration of evidence-based clinical dentistry and each case has a list of references to accompany it.

The first section of the book gives a brief introduction about how this book came about, followed by a background into conducting literature searches. Section two is entitled 'treatment planning' and the chapters in this section explore areas like consent, clinical decision making and treatment sequencing. The chapter on treatment sequencing is especially well written and sets the style, which the rest of the book follows.

Section three looks at various management options for patients. The first chapter in the section has a great piece on tooth preparation techniques. It is further complemented by the excellent enclosed CD in which the viewer can see an upper incisor being prepared for a crown live on a patient. The other chapters in this section look at provisional restorations - both short and long term - and also the importance of recalls and reviewing patients.

Section four of the book presents various cases and a significant portion of the book is dedicated to this section. Each case begins with a brief clinical introduction to the topic, which is then followed by looking at various cases. The cases are extremely well presented, looking first at the patient's clinical history, followed by the treatment option and then the sequence of treatment. There is also a discussion at the end of each case inclusive of references.

Overall, this is a well written, illustrated and referenced textbook, to critically build one's knowledge-base and inform decisions on clinical treatment. Even though this book is primarily aimed at postgraduates, it is written in such a way that most undergraduates could easily follow too.

\section{F. Amin}

\section{QDT 2012: VOL 35}

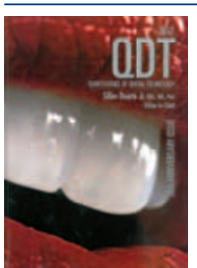

S. Duarte (ed)

UK: Quintessence

price $€ 78.00$; pp 236

ISBN 9781867155624

This beautiful book presents the heights of aesthetic dentistry. The 35th anniversary issue of $Q D T$, an annual publication, is a compilation of interesting articles reporting successes in fixed prosthodontics. The main focus of this year's issue is ultraconservative esthetic treatment and nature-inspired restorations, which will be of interest to dental technicians and any clinician keeping abreast of the advances in cosmetic dentistry. A slim, easy-to-read volume, it is generously illustrated with hundreds of glossy colour photographs.

In sixteen articles a variety of case reports and dental materials are detailed with contributions from numerous international professionals.
The material topics include accurate colour reproduction, a guide to post and core restorations and an anatomical approach to building up porcelain in crown and bridgework.

The case reports range from the routine to the very complex. Throughout the volume there is enthusiastic discussion of getting the best possible result for every tooth restored, but the real delight is the multidisciplinary cases that have enviable results. These include patients presenting with hypodontia and dentinogenesis imperfecta with reduced occlusal vertical dimension.

This is an inspiring book to read and I feel it would give any clinician the confidence to strive for a higher quality of prosthodontic work. Although some of the cases would be quite adventurous to attempt in practice, it shows there is still much to learn. I certainly feel more emboldened when examining the shape, composition and characterisation of the anterior teeth.

The articles are well referenced and guide the enthusiast towards further reading. There are tables and images throughout with a well executed stepby-step approach to clinical techniques.

Its real success is in its demonstration of multidisciplinary work where dental technology, prosthodontics, oral surgery and restorative dentistry are contributing to an impressive result for the patient. Overall this is a reminder of the beautiful outcomes that can be achieved in dentistry.

L. Murphy 